\title{
The Effect of Memory and Attention Adaptation Training on Working Memory and Processing Speed in Children Survived from Cancer
}

\author{
Nafiseh Damreihani ${ }^{1}$, Ezat Deyreh ${ }^{2, *}$, Ali Pooladi Rishehri ${ }^{3}$, Mohammad Reza Bordbar ${ }^{4}$ \\ ${ }^{1}$ Ph.D. Student of Psychology, Department of Psychology, Islamic Azad University, Boushehr, Iran. \\ ${ }^{2}$ Assistant Professor, Department of Psychology, Islamic Azad University, Boushehr, Iran \\ ${ }^{3}$ Assistant Professor, Department of Psychology, Payam-e-Noor University, Boushehr, Iran \\ ${ }^{4}$ Associate Professor, Hematology Research Center, Shiraz University of Medical Sciences, Shiraz, Iran.
}

\section{ARTICLE INFO}

\section{Article History}

Received: 30 September 2019

Revised: 7 November 2020

Accepted: 14 November 2020

Available online: February 2021

Article Type

Research Article

Keywords

Acute lymphoblastic leukemia; Cognitive Behavior Therapy; Working Memory; Processing Speed; Survived Adolescents

\section{Corresponding Author*}

Ezat Deyreh received her Ph.D. in Educational Psychology from Islamic Azad University of Science and Research, Tehran branch. She is currently an Assistant Professor in Department of Educational Psychology at Islamic Azad University of Boushehr. Her research interests are in cognitive-behavior interventions for children and adolescents.

Correspondence concerning this article should be addressed to dr. Ezat Deyreh, Department of Psychology Faculty of Graduate Education, Islamic Azad University, Next to the Teacher House, Varzesh St, Boushehr. Postal Code 7515895496.

ORCID: 0000-0003-2696-9648

E-mail: ezatdeyreh@gmail.com

doi: http://dx.doi.org/10.29252/bjcp.14.2.53

\section{ABSTRACT}

The aim of this study was to promote working memory and processing speed in adolescents surviving acute lymphoblastic leukemia with a history of chemotherapy, utilizing a cognitive behavior therapy (MAAT).

The study population of this research included 60 adolescents survived from acute lymphoblastic leukemia with chemotherapy history attending Imam Reza outpatient oncology clinic. The participants were randomly assigned to two groups of intervention group (experimental group) and waiting list (control group) ( $\mathrm{n}=30$ per group). The subjects in the experimental group were provided with 2 months Memory and Attention Adaptation Training. The data was obtained using the Wechsler Intelligence Scale for Children (WISC-4) in the three stages of pretest, post-test, and follow-up (2 months after posttest). Data analysis was performed using descriptive (mean and standard deviation) and inferential statistics (analysis of covariance) by SPSS software.

Results showed significant improvements in the scores of working memory and processing speed in the intervention group $(\mathrm{P}<0.01)$.

Therefore, it can be said that attention and memory matching training based on cognitive-behavioral approach can be effective on working memory and processing speed of children left with cancer with a history of chemotherapy.

Citation: Damreihani, N., Deyreh, E., Pooladi Rishehri, A., \& Bordbar M. R. (1399/2021). The Effect of Memory and Attention Adaptation Training on Working Memory and Processing Speed in Children Survived from Cancer. Contemporary Psychology, 14(2), 52-59. http://dx.doi.org/10.29252/bjcp.14.2.53 


\title{
تأثير آموزش تطابق توجه و حافظه بر حافظهى كارى و سرعت بردازش در كودكان سرطانى بقايافته
}

\author{
نفيسه دم ريحانى '، عزت ديره"،:"، على يولادى ريشهرى"، محمدرضا بردبارع \\ ' ' دانشجوى دكترى روانشناسى، كروه روانشناسى، واحد بوشهر، دانشخاه آزاد اسلامى، بوشهر، ايران

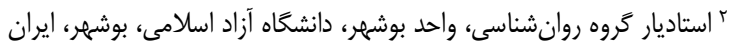

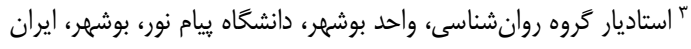

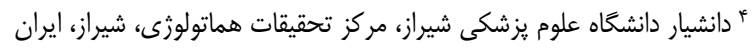

يزوهش حاضر با هدف بهبود حافظهى فعال و سرعت يردازش در كودكان و نوجوانان بقايافته از

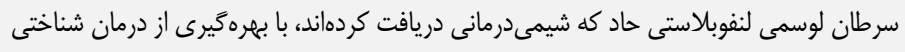
رفتارى آموزش تطابق توجه و حافظه انجام شده است.

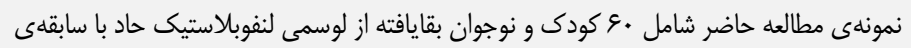

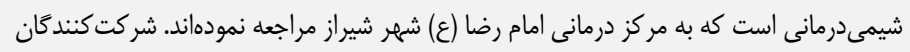

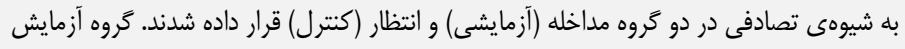

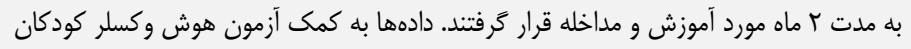

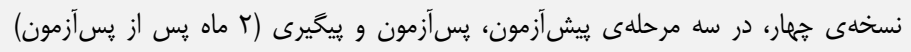

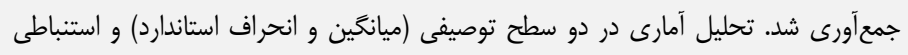
(تحليل كوواريانس) انجام شد.

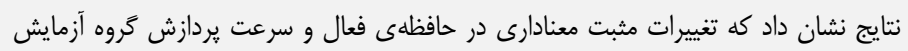

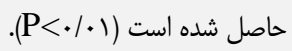
بنابراين، مىتوان كفت آموزش تطابق توجه و حافظه مبتنى بر رويكرد شناختى رفتارى، مى آواند بر حافظهى فعال و سرعت يردازش كودكان بقايافته از سرطان با سابقه شيمى مردمانى مؤثر باشد.
لوسمى لنفوبلاستى حاد، شايعترين بيمارى بدخيم در ميان

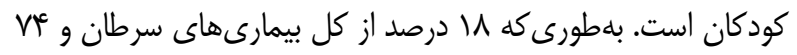

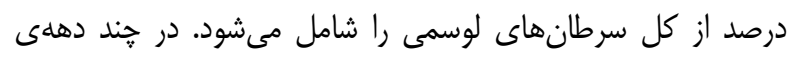

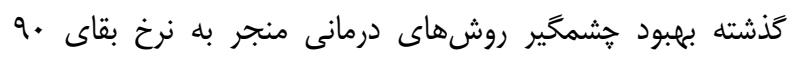

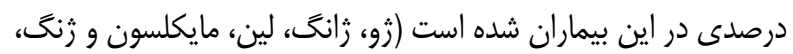

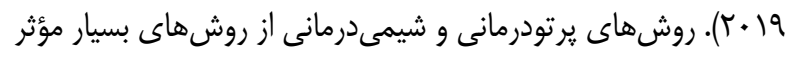

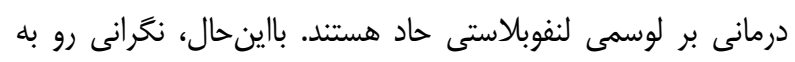

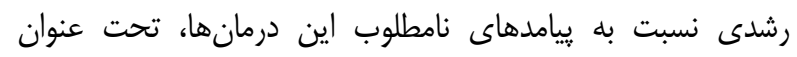

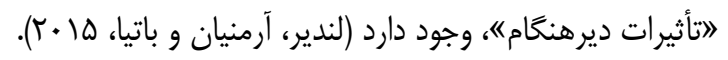

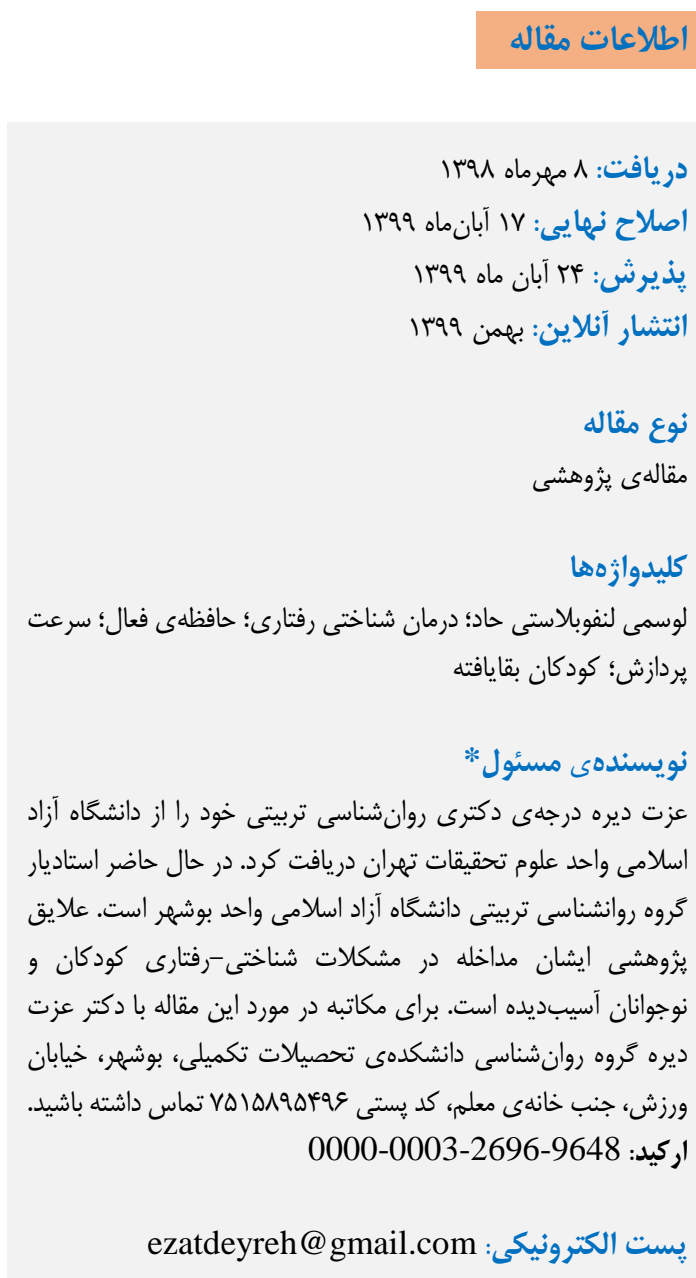

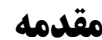

سرطان بهعنوان يك بيمارى غير واگير، يكى از دلايل اصلى

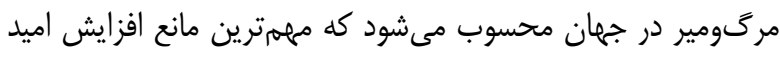

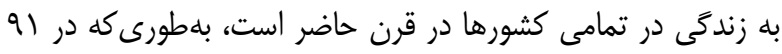

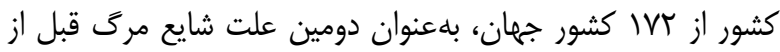

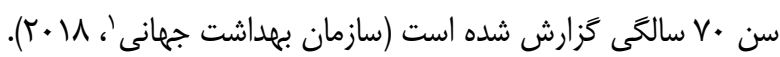

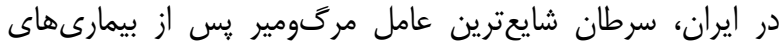
قلبى-عروقى و تصادفات و سوانح است (فرهود، جرائلى و عليزاديه، 
درمان شناختى رفتارى شامل كسب مهارت براى ايجاد تغييرات

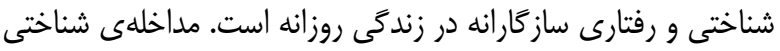

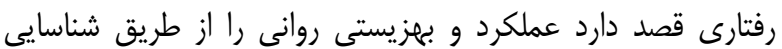

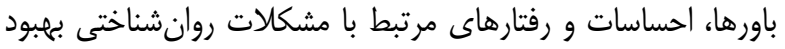

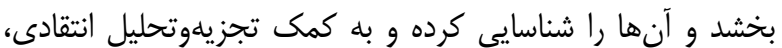

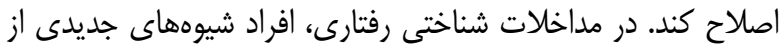

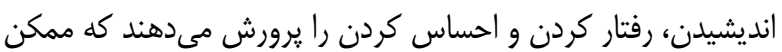

است اختلالات روانى و عاطفى را تقليل داده و يا از بين ببرد.

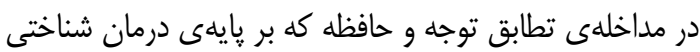

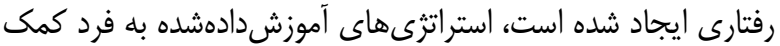

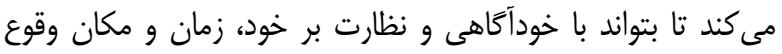

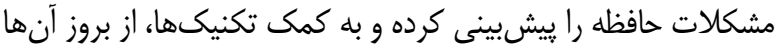

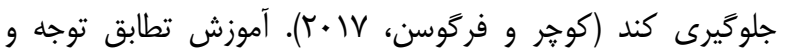

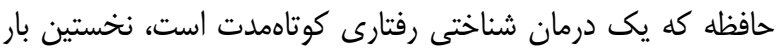

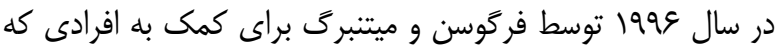

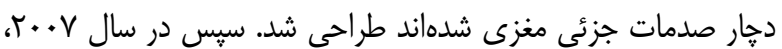

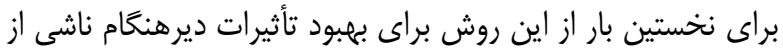

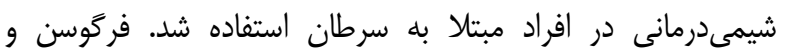

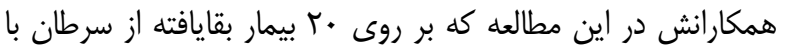
سابقهى شيمىدرمانى انجام شد، با استفاده از تكنيكهاى روش تران تطابق

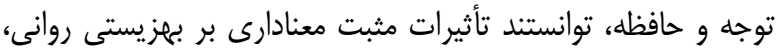
كيفيت زندگى و حافظهى آنها ايجاد كنند (مكدونالد و همكاران،

.$(r \cdot)$

مداخلات درمانى بر روى اين مهارتها بهترين راه براى ايجاد

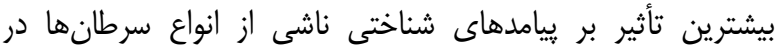

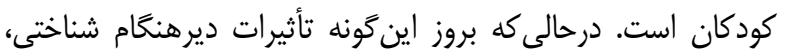

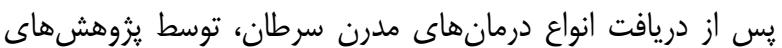

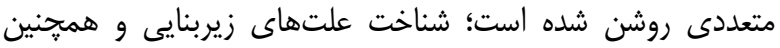

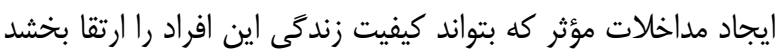

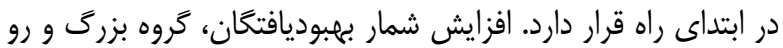
به رشدى از كودكانى را ايجاد كرده است كه ازنظر شناختى دهار آسيب

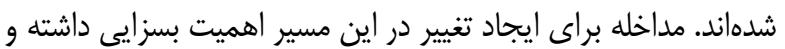

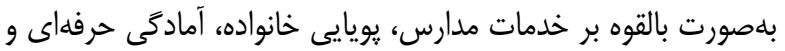

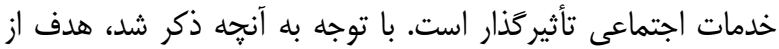

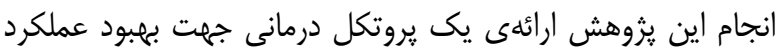

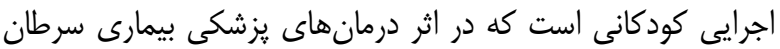
دهار تأثيرات ديرهنكام شناختى و افت عملكرد تحصيلى شدند.

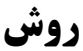

\section{طرح آزمايشى}

طرح مورداستفاده در يزوهش حاضر، از نوع نيمه آزمايشى

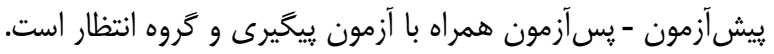

در ايجاد اين اختلالات شناختى بهعنوان عوارض جانبى ناشى

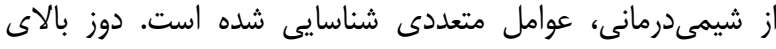

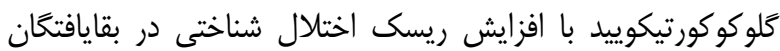

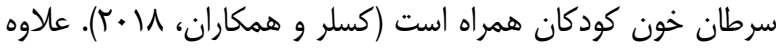

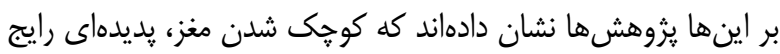

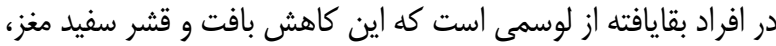

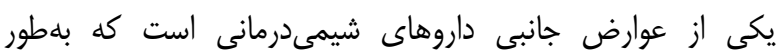

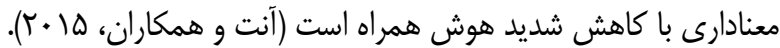
ازجملهى اين تأثيرات ديرهنكام كه يُوهشهاه

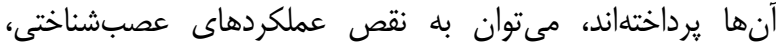
مشكلات حافظه، ضعف در عملكرد حافظهى فعال، ضعف استان استدلال ديدارى-فضايى، عدم هماهنكى حركتى، ضعف در سرعت بردئ بردازش، افت عملكرد تحصيلى و كاركردهاى اجرايى اشاره كارئ كرد (لير، بالزامو،

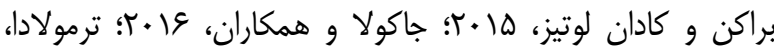

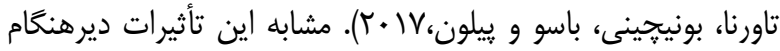

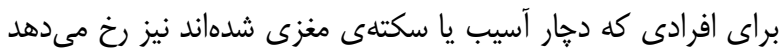
و مانند افرادى كه دهار جراحات مغزى شدهاند، كودكان بهريبوديافياته

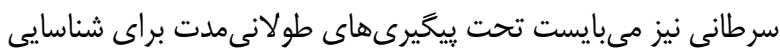

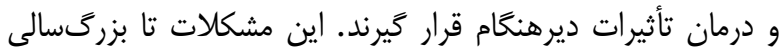

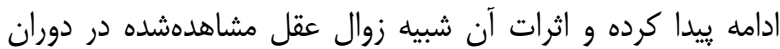

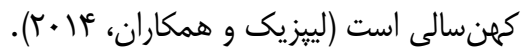
يزوهشهاى بسيارى نشان دادهاند كه بقايافتكان از بيمارى

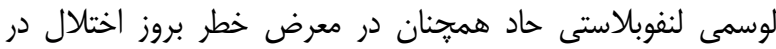

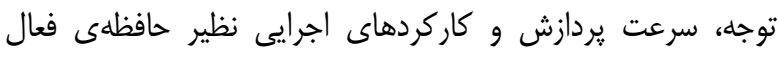

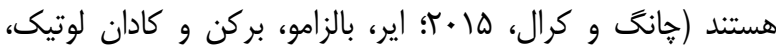

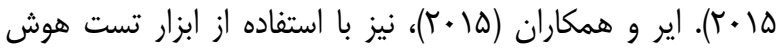

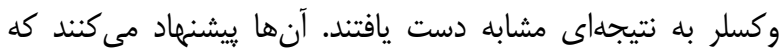

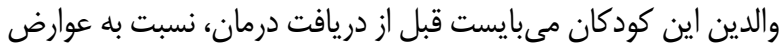

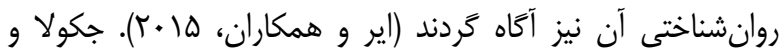

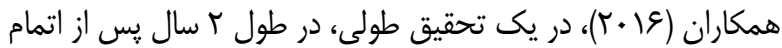

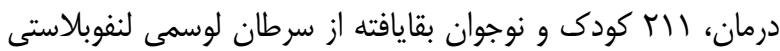

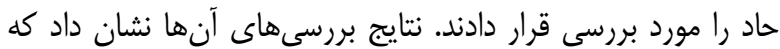

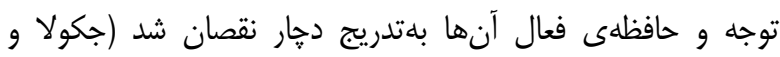

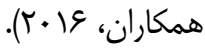

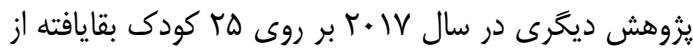
سرطان لوسمى لنفوبلاستى حاد، نشان داد كه عملكرد تحصيلى آنها

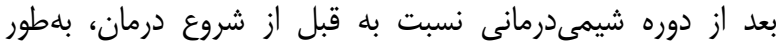

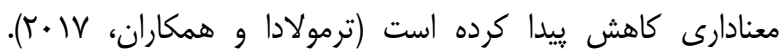

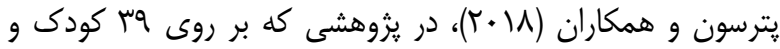

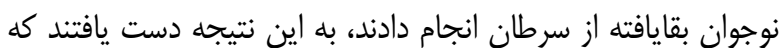

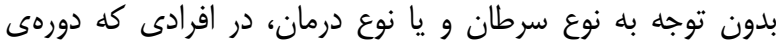

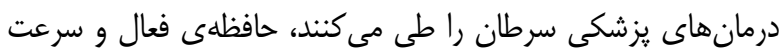

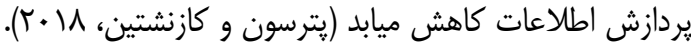


وكسلر براى بررسى ضريب اعتبار زيرمقياسها و بهرههاى

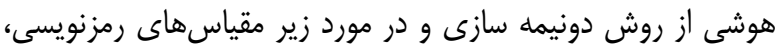

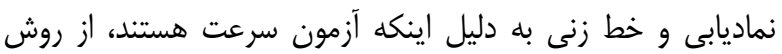

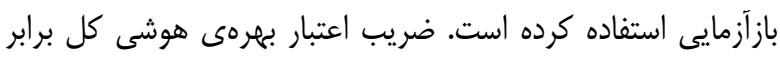

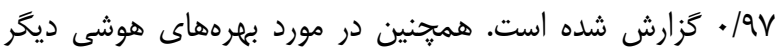

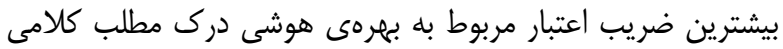

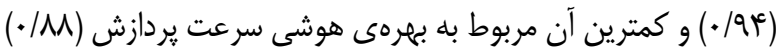

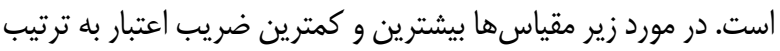

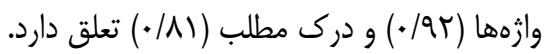

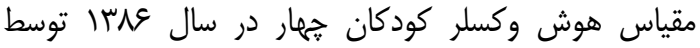
عابدى و همكاران، روى نمونهى AVT نفرى از كودكان ايرانى انطباق

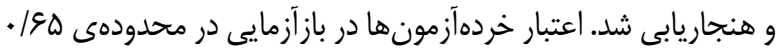
تا هو/· و ضرايب اعتبار تنصيف از ال/ • تا عN/• كزارش شده است.

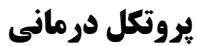

آموزش تطابق توجه و حافظه: تكنيكهايى كه در اين روش

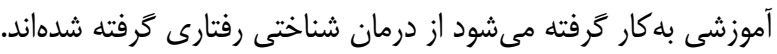

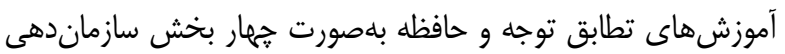
شدهاند: () آموزش درزمينهى توجه و وانظ حافظه (مشكلات شناختى

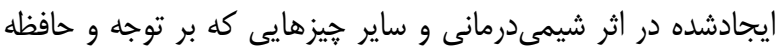

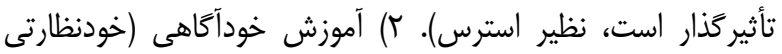
جهت تشخيص موقعيتهاى يرخطر و يا وضعيتهايى كه به به

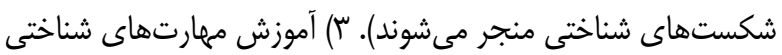

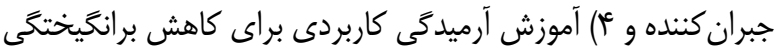

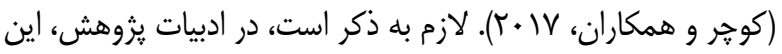

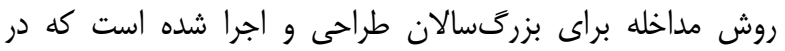

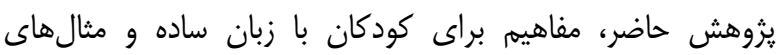
قابلفهم آموزش داده شده است.

\section{كدهاى اخلاق و كار آزمايى}

يس از طى مراحل ادارى و كرفتن مجوز براى نمونهگيرى و

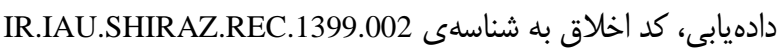
از دانشخاه آزاد اسلامى واحد شيراز و كد IRCT به شمارهى

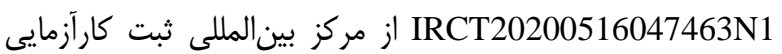

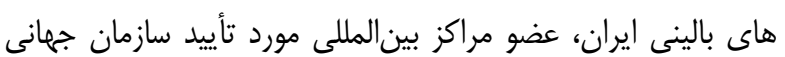

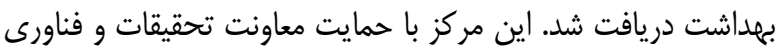

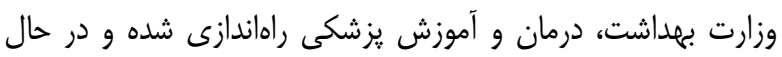

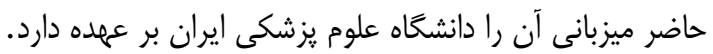

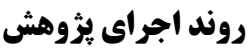

طرح يزوهش براى كليهى افراد مراجعلكننده به درمانكاه كه از

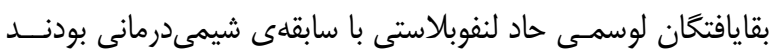

معيارهاى ورود به يثوهش شامل قرار داشتن در محدودمى

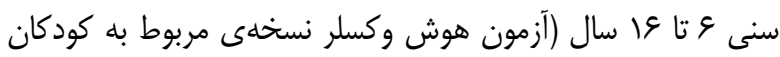
براى اين بازه سنى طراحى شده است و شرط لازم إن براى صحت صدت نتايج

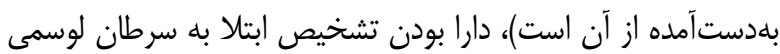

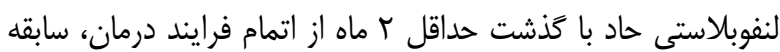
دريافت شيمىدرمانى، وجود ضعف با حداقل يك انحر اف استاندارد در متغيرهاى حافظهى فعال و سرعت يردازش، عدم ابتانلا به بيمارى هاى داى

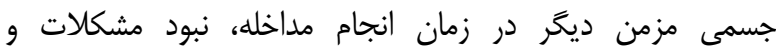

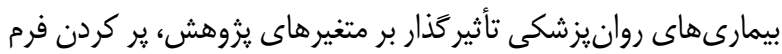

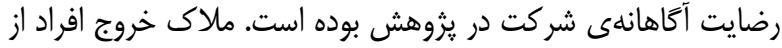
طرح يزوهشى، ابتلا به انواع ديكر سرطان (غير از لوسمى لنفوبلاستى درانى

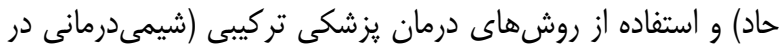

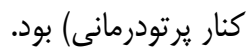

اين يزوهش بر روى •و نفر از كودكان بقايافته از لوسمى حاد لنفوبلاستيك داراى سابقهى شيمىدرمانى انجام شده است. جامعلى

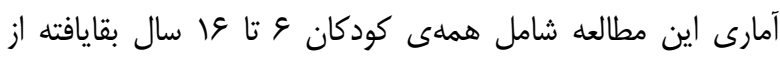

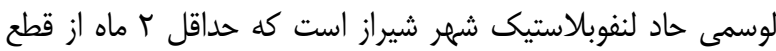

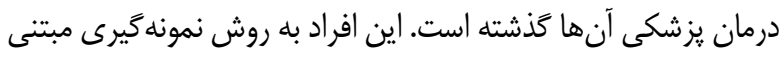

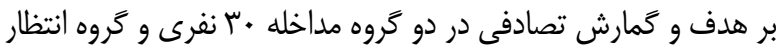

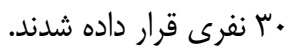

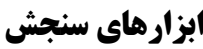

آزمون هوشى وكسلر كودكان (نسخهى جهار): وكسلر در سال

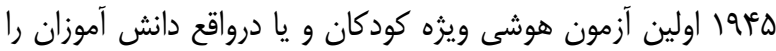

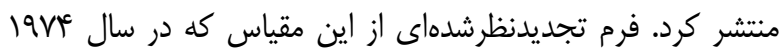

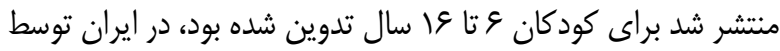

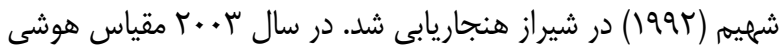
وكسلر كودكان نسخهى جهار منتشر شد. اكريه در هر تجديدنظ

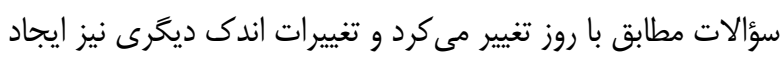

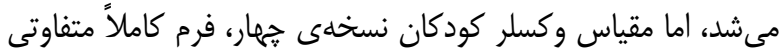
است كه در آن حتى در مفاهيم نظرى نيز تغييراتى ايجاد شده است.

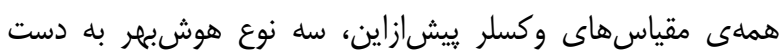

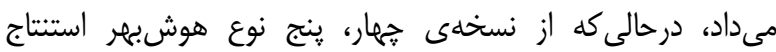

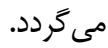
مقياس هوش وكسلر كودكان جهار شامل •ا خردمامقياس

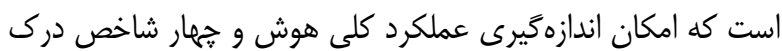

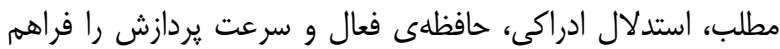

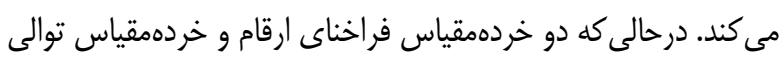

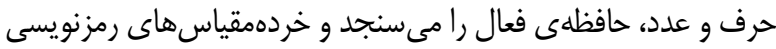
و نماديابى براى سنجش سرعت يردازش به كار مىروند. 
جدول شماره ا. محتواى يروتكل درمانى

\begin{tabular}{|c|c|}
\hline محتواى برنامه & 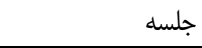 \\
\hline 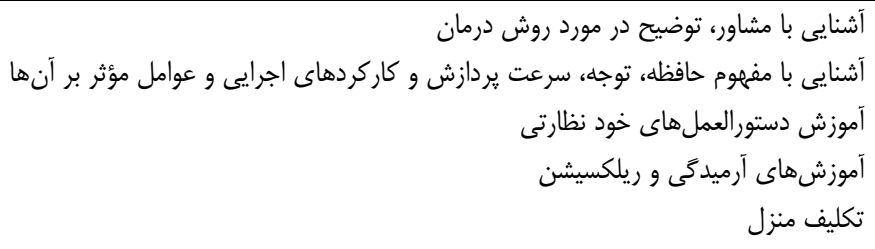 & جلسه حضورى I \\
\hline مرور تكاليف خانكى، رفع اشكال & اولين تماس تلفنى \\
\hline معرور استراتزى مهاى جبران كننده، آموزش هند مورد از آنها، تمرين منزل & جلسه حضورى r \\
\hline مرور تكاليف خانكى، رفع اشكال & دومين تماس تلفنى \\
\hline 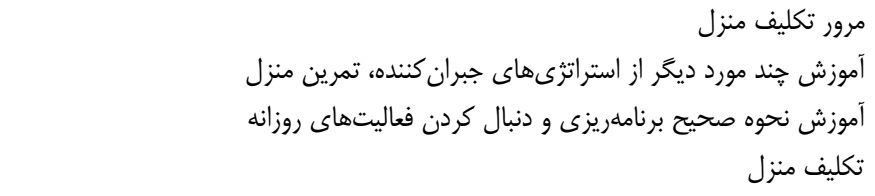 & جلسه حضورى " ( ج \\
\hline مرور تكاليف خانكى، رفع اشكال & سومين تماس تلفنى \\
\hline 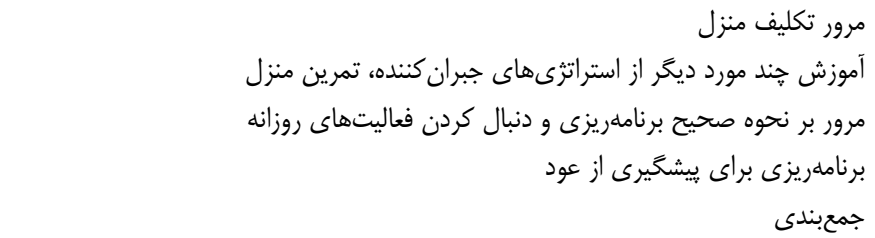 & جلسه حضورى f \\
\hline
\end{tabular}

همتاسازى شدهاند (جدول r). همجنين هملهى آزمودنىها در كذشتها

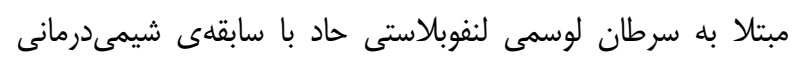
بودهاند كه حداقل r ماه از قطع درمان يزشكى آنها كَذشته است.

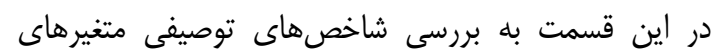

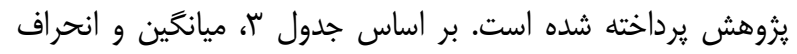

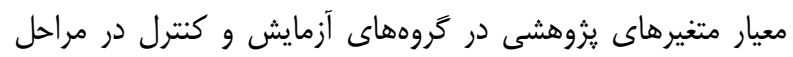
مختلف اجراى يزوهش آمده است. بلمنظور استفاده از تحليل كوواريانس برائ مقايسهى ميانكين

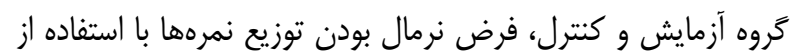

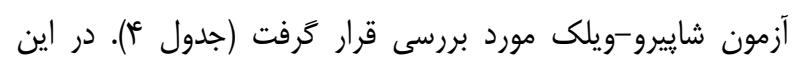

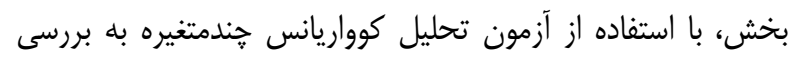

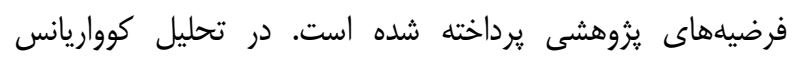

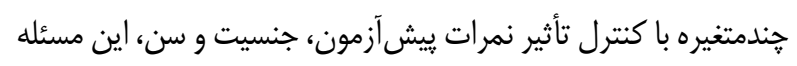

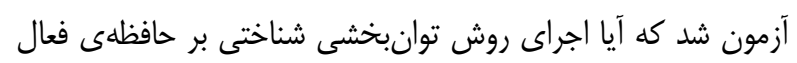
و سرعت بردازش اثر كذار بوده است يا خير.
توضيح داده شد و از افرادى كه مايل به شركت بودند، فرم رضايت

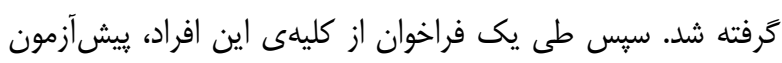

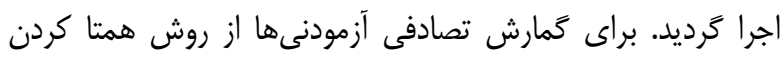

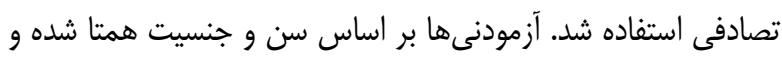

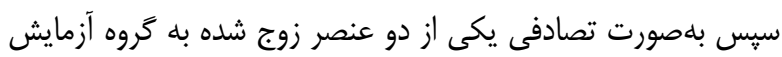

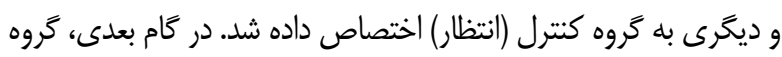

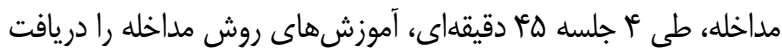

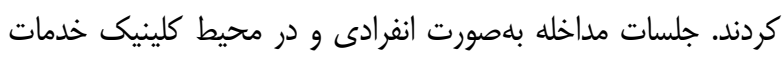

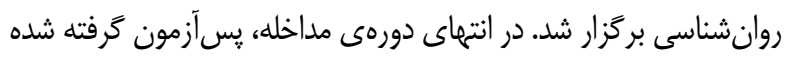

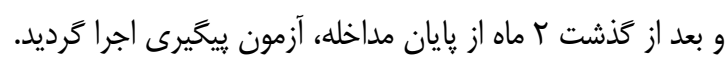

\section{نتايج}

در اين بخش، نمونهى موردمطالعه بر اساس ويزَى هاى جمعيت

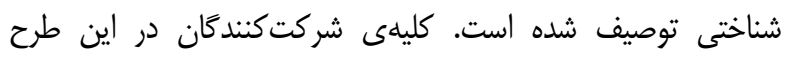

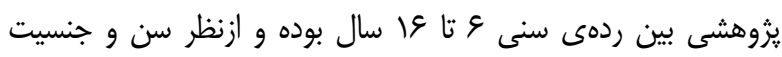

\begin{tabular}{|c|c|c|c|c|c|c|}
\hline \multicolumn{2}{|c|}{ كل كل } & \multicolumn{2}{|c|}{ يسران } & \multicolumn{2}{|c|}{ دختران } & \multirow{2}{*}{ كروه } \\
\hline درصد & تعداد & درصد & تعداد & درصد & تعداد & \\
\hline$\Delta \cdot$ & $r$. & $\Delta \cdot$ & 10 & $\Delta \cdot$ & 10 & كروه آموزشى \\
\hline$\Delta \cdot$ & $r \cdot$ & $\Delta \cdot$ & 10 & $\Delta \cdot$ & 10 & كروه كنترل \\
\hline $1 \ldots$ & c. & $1 \cdots$ & $r$. & $1 \ldots$ & r. & كل \\
\hline
\end{tabular}




\begin{tabular}{|c|c|c|c|c|c|}
\hline \multicolumn{2}{|c|}{ كروه كنترل } & \multicolumn{2}{|c|}{ كروه مداخله } & & \multirow{2}{*}{ متغير وابسته } \\
\hline انحراف استاندارد & ميانگين & انحراف استاندارد & ميانگين & & \\
\hline r/GFY & $11 / 9$. & $r / I V T$ & $I T / T \Delta$ & يِيشآزمون & \\
\hline$r / 9.9$ & $11 / \omega$. & $r / D I I$ & $18 / 9$. & מֶ آزمون & حافظهى فعال \\
\hline r/gat & $11 / 8$. & $\Gamma / \Delta \wedge \Delta$ & $18 / 90$ & ييخيرى & \\
\hline V/rT. & $\Delta) / V$. & $s|\Delta \wedge|$ & $\Delta) / \omega$. & يِش آزمون & \\
\hline $8 / 909$ & $\Delta 1 / V$. & $g|\wedge|$. & $\Delta \Delta / T$. & يس آَزمون & سرعت بردازش \\
\hline$V / \cdot v^{c}$ & $\Delta 1 / \kappa$. & s/Wr & $\Delta Q / \Delta \Delta$ & ييخيرى & \\
\hline
\end{tabular}

جدول شماره أ. نتيجهى آزمون شاييرو-ويلك براى بررسى نرمال بودن دادهها

\begin{tabular}{|c|c|c|c|c|c|}
\hline \multicolumn{2}{|c|}{ گروه كنترل } & \multicolumn{2}{|c|}{ كروه آزمايش } & \multirow{2}{*}{ مرحلهى اجرا } & \multirow{2}{*}{ متغيرها } \\
\hline معنادارى & آمارهى توزيع & معنادارى & آمارهى توزيع & & \\
\hline . IEr & •/IrI & . /9m5 &.$/ 11$ & يسآزمون & \multirow{2}{*}{ حافظهى فعال } \\
\hline . &.$/ 19$. & TH & וזו/. & ييخيرى & \\
\hline - IVE &.$/ 1$. & $\cdot / K I D$ &.$/ 19$. & يسآزمون & \multirow{2}{*}{ سرعت يردازش } \\
\hline.$/ 4 \& \Lambda$ &.$/ 11 V$ & ع צ &.$/ 191$ & ييخيرى & \\
\hline
\end{tabular}

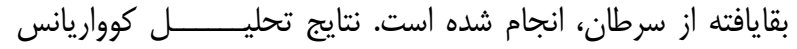

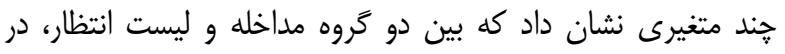

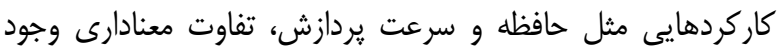

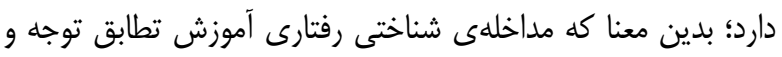

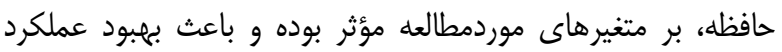

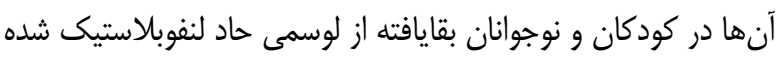
است و در مرحلهى بيخيرى نيز ثبات داشته است. اين نتايج با يزوهشهاى متعددى كه در سالهاى اخير انجام شده

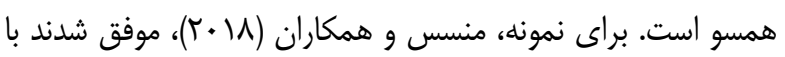

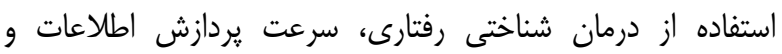

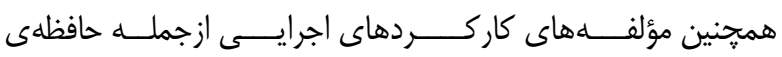

نتايج نشان داد كه بين حافظهى فعال و سرعت يردازش

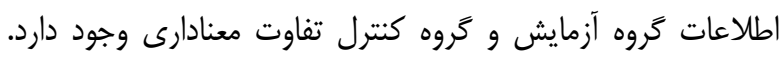
درواقع شركت در جلسات آموزش تطابق توجه و حافظه توانسته است موجب ارتقاى حافظهى فعال و سرعت يردازش شود و ورد درنتيجه

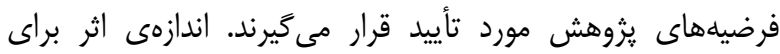

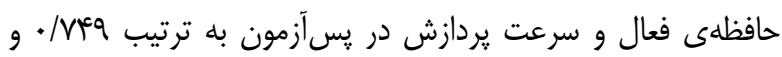
. • است.

\section{بحث و نتيجه كيرى}

يزوهش حاضر، با هدف ارائهى يك مداخله براى بهبود

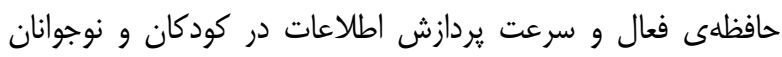

جدول شماره ه. نتايج آزمون تحليل كوواريانس جندمتغيره براى تفاوت ميانگينها در گروههاى آزمايش و كنترل

\begin{tabular}{|c|c|c|c|c|c|c|}
\hline ضريب ايتا & معنادارى & $\mathrm{F}$ & درجهى آزادى & مجموعهى مجذورات & متغيرهاى وابسته & منبع \\
\hline$\cdot / V<q$ & $\cdot / \cdot \cdot 1$ & 9N/DTI & $r$ & $r \Delta \Delta / r \Delta$ & يسآزمون حافظهى فعال & كروه \\
\hline$\cdot|A| T$ & $\cdot / \cdot 1$ & $1 \cdot 9 / A \vee 1$ & r & THT/I & ييحيرى حافظهى فعال & \\
\hline$\cdot \mid 9 \wedge \Lambda$ & $\cdot 1 \cdot \cdot 1$ & $\Delta G / T F V$ & r & FVN/F. & ֶسآزمون سرعت يردازش & \\
\hline \multirow[t]{9}{*}{. NGT } & $\cdot 1 \cdot \cdot 1$ & $V T / F Q D$ & r & $\Delta G F / T$ & ييخيرى سرعت يردازش & \\
\hline & & $1 / 799$ & $\Delta 1$ & $991 \cdot 1$ & يسآزمون حافظهى فعال & خطا \\
\hline & & $1 / \cdot \Delta q$ & $\Delta 1$ & $\Delta F / \Lambda V$ & ييخيرى حافظهى فعال & \\
\hline & & $F / T F \Delta$ & QI & ris/a. & پِآزمون سرعت يردازش & \\
\hline & & r/AF. & Q1 & 19D/Ar & ييخيرى سرعت يردازش & \\
\hline & & & 4 . & $|\nvdash \varepsilon \Delta r| \ldots$ & ״سآزمون حافظهى فعال & كل \\
\hline & & & 4. & $|\& \& q v| \ldots$ & ييخيرى حافظهى فعال & \\
\hline & & & 4. & $\Delta \Delta \vee \& 9 q / \cdots$ & پسآزمون سرعت يردازش & \\
\hline & & & 4 . & $\Delta \Delta \& \varepsilon \cdot q / \ldots$ & ييخيرى سرعت يردازش & \\
\hline
\end{tabular}


بيشيينى كنندهى موفقيت در يادگيرىهاى يك سال بعد در

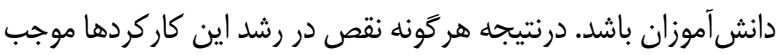
اختلال در برنامهريزى براى شروع، اتمام تكليف و به يادسيارى تكاليف دارك

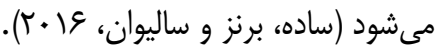

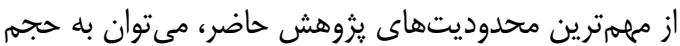

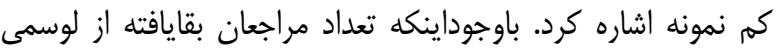

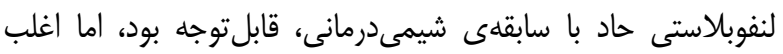

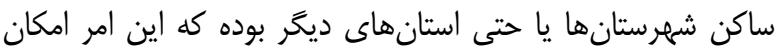

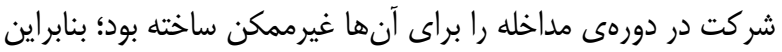

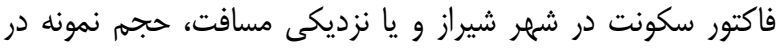

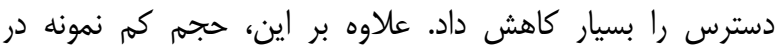

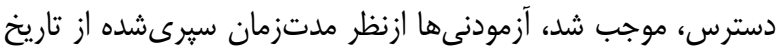

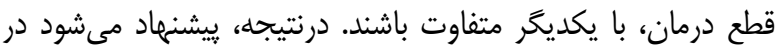

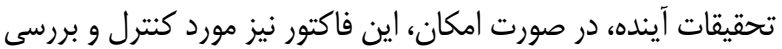

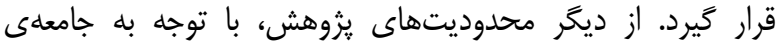
موردمطالعه كه شامل كودكان و نوجوانان محصل است، برنامهريزى براى زمان مناسب جهت اجراى مداخله بود.

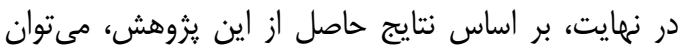

اظظهار داشت كه درمان شناختى رفتارى تطابق توجه و حافظه، مى تواند

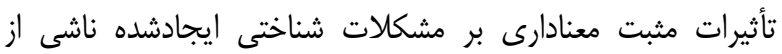
شيمىدرمانى در افراد بقايافته از سرطان داشته باشد.

در صورت تأييد نتايج اين تحقيق در مداخلات مرتبط با بان إنان تغييرات مؤلفههاى شناختى در كودكان و نوجوانان مبتلا به سرطان،

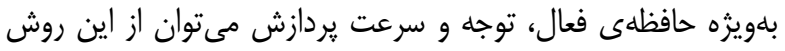

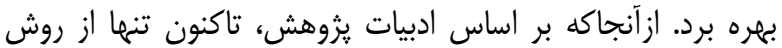

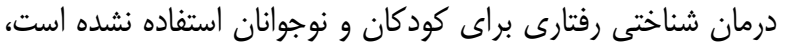
در صورت تأييد نتايج روش تطابق براي توجه و و حافظه كه بركَان

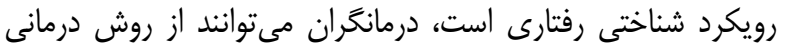

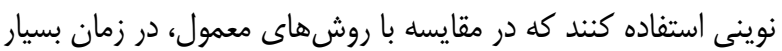

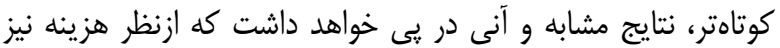
براى خانوادههاى اين افراد مقرونبهصرفه خواهد بود.
فعال را در •و زن بقايافته سرطان پِستان بهبود بخشند (منسس و و

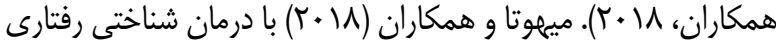

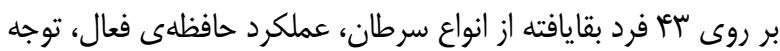

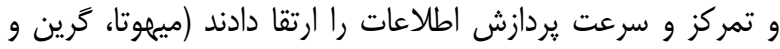

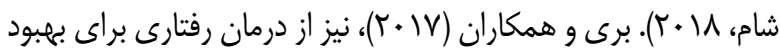

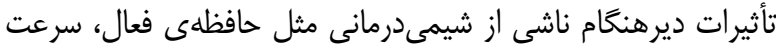

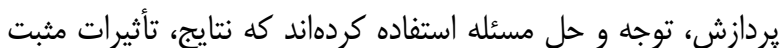

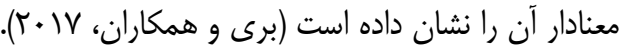

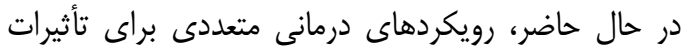
ديرهنگام ناشى از شيمىدرمانى بهكار كَرفته شدهاند؛ از درمانهان

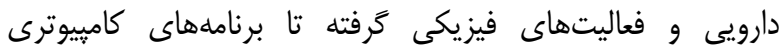

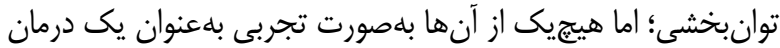

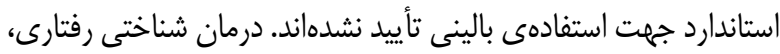
يك رويكرد عملى براى تقويت عملكرد شناختى و بهبود كيفيت زندكى

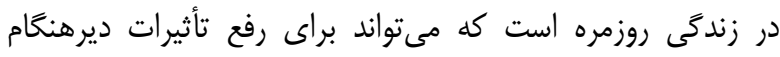
شناختى در طولانىمدت به كار رود. نتايج بسيارى اثركذارى رون روش

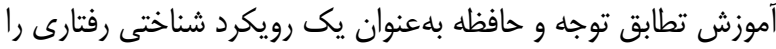

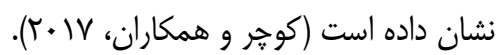
بروز اختالال در حافظهى فعال احتمال مشكلات سازكارى

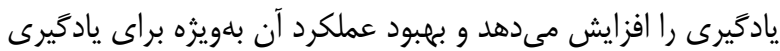
و عملكرد مطلوب در موضوعات تحصيلى بسيار حائز اهميت است. حافظهى فعال در اكتساب مهارتهايى كه موجب فرايندهاى خواندن،

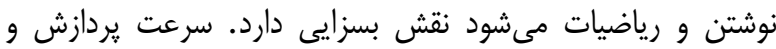

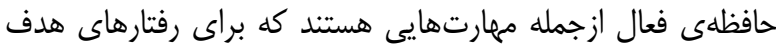
محور لازم و ضرورى است. ازأنجاكه حافظهى فعال امكان

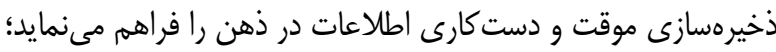
كاركرد اين مؤلفه بهمنظور تسهيل و انجام صحيح فعاليت ساير داري

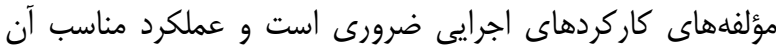

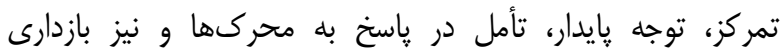

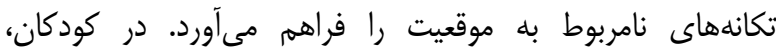
مهارتهاى حافظهى كارى و سرعت بردازش، بيش از هوش مى تونواند

قدردانى: بر خود لازم مى دانيم از تمامى خانوادههاى عزيزان شركت كننده در اين بروهش و همجنين كادر درمانى و ادارى مركز درمانى امام رضا (ع) شهر شيراز كه ما رادر

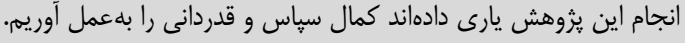

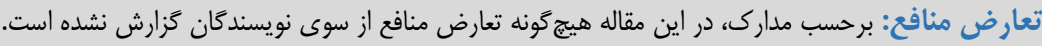

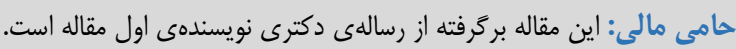

\section{Reference}

Annett, R. D., Hile, S., Bedrick, E., Kunin-Batson, A. S., Krull, K. R., Embry, L., Maclean, W., Noll, R. (2015). Neuropsychological functioning of children treated for acute lymphoblastic leukemia: impact of whole brain radiation therapy. Psychooncology, 24(2), 181-189. [DOI:10.1002/ pon.3586] [PMid:24890730]
Bray, V. J., Dhillon, H. M., Bell, M. L., Fiero, M. H., Yip, D., Boyle, F., Price, M. A. \& Vardy, J. L. (2017). Evaluation of a web-based cognitive rehabilitation program in cancer survivors reporting cognitive symptoms after chemotherapy. J Clin Oncol, 35,217-225. [DOI:10.1200/JCO. 2016.67.8201] [PMid:28056205] 
Cheung, Y. T., \& Krull, K. R. (2015). Neurocognitive outcomes in long-term survivors of childhood acute lymphoblastic leukemia treated on contemporary treatment protocols: A systematic review. Neurosci Biobehav Rev, 53,108-120. [DOI: 10.1016/j.neubiorev. 2015. 03.016] [PMid: 25857254 PMCid: PMC4425605]

Farhood, B., Geraily, Gh., \& Alizadeh, A. (2018). Incidence and Mortality of Various Cancers in Iran and Compare to Other Countries: A Review Articl. Iran J Public Health, 47(3), 309-316. [In Persian, 1396]

Iyer, N. S., Balsamo, L. M., Bracken, M. B., \& Kadanlottick, N. S. (2015). Chemotherapy-only treatment effects on long-term neurocognitive functioning in childhood all survivors: A review and meta-analysis. Blood, 126, 346-354. [DOI: 10.1182/blood-2015-02-627414] [PMid:26048910]

Jacola, L. M., Krull, K. R., Pui, C. H., Pei, D., Cheng, C., Reddick, W. E., \& Conklin, H. M. (2016). Longitudinal assessment of neurocognitive outcomes in survivors of childhood acute lymphoblastic leukemia treated on a contemporary chemotherapy protocol. Journal of Clinical Oncology: Official Journal of the American Society of Clinical Oncology, 34, 1239- 1247. [DOI: 10.1200 / JCO. 2015. 64. 3205] [PMid: 26858334 PMCid: PMC4872325]

Kesler, S. R., Ogg, R., Reddick, W.E., Phillips, N., Scoggins, M., \& Glass, J. O. (2018). Brain Network Connectivity and Executive Function in Long-Term Survivors of Childhood Acute Lymphoblastic Leukemia. Brain Connectivity, 8(6), 333-342. [DOI:10.1089/brain.2017.0574] [PMid:29936880 PMCid:PMC6103246]

Kucherer, S., \& Ferguson, F. J. (2017). Cognitive behavioral therapy for cancer related cognitive dysfunction. Curr Opin Support Palliat Care, 11(1), 46-51. [DOI: 101097 / SPC. 0000000000000247] [PMid: 27898511 PMCid: PMC5285475]

Landier, W., Armenian, S. \& Bhatia, S. (2015). Late effects of childhood cancer and its treatment. Pediatric Clinics of North America, 62, 275-300. [DOI:10.1016/j.pcl.2014.09.017] [PMid:25435123]

Lipszyc, J., Levin, H., Hanten, G., Hunter, J., Dennis, M., \& Schachar, R. (2014). Frontal white matter damage impairs response inhibition in children following traumatic brain injury. Archives of Clinical Neuropsychology: The Official Journal of the National Academy of Neuropsychologists, 29, 289-299. [DOI:10.1093/arclin/acu004] [PMid: 24618405 PMCid:PMC4000231]

Lyer, N. S., Balsamo, L. M., Bracken, M. B., \& KadanLotticz, N. S. (2015). Chemotherapy-only treatment effects on long-term neurocognitive functioning in childhood ALL survivors: a review and metaanalysis. Blood, 126 (3), 346-353. [DOI: 10.1182 /blood-2015-02-627414] [PMid:26048910]

McDonald, B. C., Flashman, L. A., Arciniegas, D. B., Ferguson, R. J., Xing, L., Harezlak, J., Sprehn, G. C. (2017). Methylphenidate and Memory and Attention Adaptation Training for Persistent Cognitive Symptoms after Traumatic Brain Injury: A Randomized, Placebo-Controlled Trial. Neuropsychopharmacology, 42, 1766-1775. [DOI: 10.1038 / npp.2016.261] [PMid:27874023 PMCid:PMC5520776]

Meneses, K., Benz, R., Bail, J. R., VO, J. B, Triebel, K., Fazeli, P., Frank, J. \& Vance, D. E. (2018). Speed of processing training in middle-aged and older breast cancer survivors (SOAR): results of a randomized controlled pilot. Breast Cancer Res Treat, 168, 259-267. [DOI:10.1007/ s10549-0174564-2] [PMid:29128897 PMCid:PMC5823754]

Mihuta, M. E., Green, H. J. \& Shum, D. H. K. (2018). Efficacy of a web-based cognitive rehabilitation intervention for adult cancer survivors: a pilot study. Eur J Cancer Care, 27(2), 1-11. [DOI:10.1111/ecc.12805] [PMid:29314350]

Peterson, R. K. \& Katzenstein, J. M. (2018). Working memory and processing speed among pediatric brain tumor patients treated with photon or proton beam radiation therapy. Children's Health Care. 48(2), 131-141 [DOI: 10.1080 / 02739615. 2018. 1510330]

Sadeh, S., Burns, K., \& Sullivan, L. (2016). "Examining an Executive Function Rating Scale as a Predictor of Achievement in Children at Risk for Behavior Problems". School Psychology Quarterly, 27(4), 236- 246. [DOI: 10. 1037/ spq0000012] [PMid: 23294237]

Shahim, S. (1992). Normalization of Children's IQ and Kessler Scale in Shiraz. Journal of Social Sciences and Humanities, Shiraz University, No. 13 \& 14, 123-154. [in Persian].

Tremolada, M., Taverna, L., Bonichini, S., Basso, G., \& Pillon, M. (2017). Self-Esteem and Academic Difficulties in Preadolescents and Adolescents Healed from Paediatric Leukaemia. Cancers, 9 (55), 1-13. [DOI : 10 . $3390 /$ cancers 9060055] [PMid:28538707 PMCid:PMC5483874]

World Health Organization. Global Health Observatory. Geneva: World Heal Organization. (2018). who.int/gho/database/en/. Accessed June 21.

Zhou, C., Zhuang, Y., Lin, X., Michelson, A. D., \& Zhang, A. (2019). Changes in neurocognitive function and central nervous system structure in childhood acute lymphoblastic leukaemia survivors after treatment: a meta-analysis. British Journal of Haematology, 187(5), 1-17. 